\title{
DAMPAK PERILAKU BULLYING TERHADAP HARGA DIRI (SELF ESTEEM) REMAJA DI PEKANBARU
}

\author{
Saniya \\ Universitas Abdurrab Jl. Riau Ujung No. 73 Tampan \\ Email : saniya@univrab.ac.id
}

\begin{abstract}
The value of self-worth is the assessment performed by individuals to themselves associated with individuals, and bullying can occur anywhere, in the school environment and in public. The aggressive behavior (bullying) has caused various physical and psychic effects, psychological effects such a psychological trauma, fear, insecurity revenge, erosion, coordination, creativity, loss of intiative, and endurance of students, declining confidence, and the pressure of the dismay. The purpose of this study is to identify the repercussions of bullying for the young self (self esteem) the young man in the new SMAN 5 Pekanbaru. The design of this research is a descriptive clarity with a cross sectional approach. Analysis of what was used was a univariate analysis and bivariat using the chi-square test using the teesampling technique. There is an effect of bullying behavior against the youth's self-esteem, with the value of $p$ value $=0.010<0.05$. it is hoped that this study can give knowledge and insight for the people who are a youth, so that it can lower their level of aggressive behavior (bullying).

Keywords : self esteem, bullying
\end{abstract}

\begin{abstract}
ABSTRAK
Harga diri adalah penilaian yang dilakukan oleh seseorang individu untuk dirinya berkaitan dengan individu, dan bullying bisa terjadi di mana saja, di lingkungan sekolah maupun di tempat umum. Perilaku agresif (bullying) yang terjadi mengakibatkan berbagai dampak fisik dan psikis, dampak psikologis seperti trauma psikologis, rasa takut, rasa tidak aman, dendam, menurunnya semangat belajar, daya konsentrasi, kreativitas, hilangnya inisiatif, serta daya tahan (mental) siswa, menurunnya rasa percaya diri, dan adanya tekanan beban fikrian. Tujuan penelitian ini adalah untuk mengetahui dampak perilaku bullying terhadap harga diri (self esteem) remaja di SMAN 5 Pekanbaru. Rancangan penelitian ini adalah deskriptif kolerasi dengan pendekatan cross sectional. Analisis yang digunakan adalah analisis univariat dan bivariat melalui uji Chi-Square dengan menggunakan tekhnik pengambilan snowball sampling. Terdapat dampak perilaku bullying terhadap harga diri remaja, dengan nilai $\mathrm{p}$ value $=0.010<0.05$. Diharapkan penelitian ini dapat memberi pengetahuan dan wawasan bagi responden yaitu remaja, sehingga dapat menurunkan tingkat perilaku agresif (bullying) sesama remaja.

Kata Kunci : self esteem, bullying
\end{abstract}

\section{PENDAHULUAN}

Masa remaja adalah masa yang sangat penting dalam kehidupan manusia, masa remaja merupakan masa peralihan antara masa anak-anak dan masa dewasa yang ditandai dengan timbulnya perubahan fisik dan psikis, keinginan bebas dari kekuasaan, rasa ingin tahu, mencari dan menemukan identitas diri, pembentukkan teman sebaya dan sebagainya, Sehingga mempengaruhi perkembangan self esteem (Santrock, 2007).

Self esteem adalah penilaian yang dilakukan oleh seseorang individu terhadap 
dirinya sendiri yang berkaitan dengan diri individu sendiri, penilaian tersebut biasanya mencerminkan penerimaan atau penolakan terhadap dirinya dan menunjukkan seberapa jauh individu itu percaya bahwa dirinya mampu akan berhasil, merasa penting, serta merasa berharga. Pada masa ini juga seseorang akan mengenali dan megembangkan seluruh aspek dalam dirinya, sehingga menentukan apakah ia akan memiliki self esteem yang positif atau negatif (Noordjanah, 2013).

Maslow mencatat dua versi kebutuhan self esteem, yaitu positif dan negatif, Self esteem yang positif akan membangkitkan rasa percaya diri, penghargaan diri, rasa yakin akan kemampuan diri, rasa berguna serta rasa bahwa kehadiran nya diperlukan didalam dunia ini, berbeda dengan Self esteem yang negatif akan memandang dirinya negatif merasa dirinya tidak berharga tidak berguna dalam segi apapun, hal ini membuat anak tidak mampu menjalin hubungan dengan temannya, sehingga anak mudah marah dan tersinggung, dan akan mudah menyakiti orang lain. Norma kelompok juga dapat membuat perilaku bullying muncul yang pada akhirnya membuat perilaku tersebut menjadi berkembang (Boyle 2008).

Bullying bisa terjadi dimana saja, di lingkungan sekolah maupun ditempat umum. Beberapa tahun terakhir ini bullying mulai marak dibicarakan termasuk bullying yang dilakukan di sekolah. Menurut Liu \& Graves, (2011). Pada awal tahun 2015 tahun lalu kembali bermunculan kasus-kasus bulyying dikalangan remaja yang kasusnya semakin parah dan memperhatinkan. Data kasus bullying di amerika serikat dilaporkan oleh josephon institute of ethinics yang melakukan survei pada 43000 remaja, hasilnya $47 \%$ remaja yang berusia $15-18$ tahun telah bullying dan 50\% dari remaja tersebut menggangu, menggoda, mengejek siswa lain.Selain di amerika di Negara kita sendiri di Indonesia di dapatkan bahwa 10$60 \%$ siswa melaporkan telah menjadi korban bullying, mereka mendapat cemoohan, ejekan, pengucilan, pemukulan dan tendangan sekurang-kurangnya sekali dalam seminggu.

Di Indonesia kasus bullying di sekolah menduduki peringkat teratas pengaduan masyarakat ke Komisi Perlindungan Anak Indonesia (KPAI) dari sektor pendidikan. KPAI mencatat 369 pengaduan terkait bullying dari Januari 2011 sampai Agustus 2014. Jumlah itu sekitar $25 \%$ dari total pengaduan di bidang pendidikan sebanyak 1.480 kasus. Bullying yang disebut KPAI sebagai bentuk kekerasan di sekolah mengalahkan tawuran pelajar, diskriminasi pendidikan, ataupun aduan pungutan liar (Firmansyah, 2014). Setyawan (2014) menambahkan 3 bahwa kasus bullying di sekolah merupakan fenomena gunung es, yaitu kejadian yang terjadi jauh lebih banyak dari yang terlihat di permukaan, karena kasus yang dilaporkan hanya sebagian kecil. KPAI juga menyebutkan bahwa kasus bullying yang menimpa anak-anak di Indonesia, baik di perkotaan dan pedesaan hampir sama rata kasusnya (Syarifah, 2014).

Menurut Andri Priyatna (2010) menyebutkan beberapa dampak buruk yang dapat terjadi pada anak yang menjadi korban bullying, antara lain kecemasan, merasa kesepian, rendah diri, tingkat kompetensi sosial yang rendah, depresi, penarikan sosial, kabur dari rumah, konsumsi alkohol dan obat-obatan yang terlarang,bunuh diri. Bullying ini bisa terjadi di sekolah negeri, swasta, bahkan sekolah bertaraf internasional (Setyawan, 2014).

Yayasan Sejiwa, (2008), bentuk bullying ada 3 macam, antara lain; bullying fisik, bullying verbal dan bullying mental/psikologis. Sedangkan menurut Bauman (2008), Ada tiga perilaku bullying yaitu overt bullying (intimidasi terbuka), indirect bullying (intimidasi tidak 
langsung), cyberbullying (intimidasi melalui dunia maya). Hasil survey pendahuluan yang dilakukan di SMAN 7 Pekanbaru dengan membagikan kuesioner sederhana kepada 10 siswa, telah ditemukan sebanyak 9 dari 10 orang siswa mengaku pernah melakukan bullying. Perilaku bullying yang paling sering JOM Vol 2 No 2, Oktober 20151151 dilakukan adalah dengan cara verbal yaitu mengejek, menjuluki dengan julukan yang tidak baik dan menyebar gossip. Bullying secara fisik yang paling sering ditemukan adalah memukul, mendorong, meninju, melempar dan menjambak. Berdasarkan fenomena yang telah diuraikan tersebut bahwa perilaku bullying terjadi di kehidupan pergaulan remaja terutama di lingkungan sekolah. Sehingga dapat disimpulkan bahwa perilaku bullying terdiri dari verbal bullying, bullying fisik, bullying mental/psikologis dan cyberbullying.

Kasus perundungan atau bullying terhadap pelajar oleh sesama temannya di sekolah terjadi di Kota Pekanbaru. Hal ini dialami AA usia 16 tahun, siswa kelas III (Kelas XII) SMA Negeri 5 Pekanbaru. siswa AA mendatangi Kantor Walikota Pekanbaru dan mengtakan teman-teman di sekolahnya memanggil dan menggapnya gila, akibatnya AA tiga hari tidak masuk kesekolah (Data Riau, 2017).

Hasil survey pendahuluan yang dilakukan peneliti melakukan pembagian kuisioner dengan 10 orang siswa dari masing-masing kelas XIPSI di SMAN 5 Pekanbaru, dari 10 siswa tersebut mengatakan bahwa ada yang pernah menjadi korban bullying tiga siswa mengatakan pernah di soraki tanpa sebab, dua siswa mengaku pernah dipermalukan teman nya,satu siswa mengatakan sering dihina teman sekolahnya, peneliti jugak mewawancarai guru BK, ia mengatakan bahwa salah satu siswa kelas X,IPS3, pernah datang ke guru BK mengaku sering menangis di mintai uang oleh teman sekolahnya hingga takut kesekolah. Guru BK jugak mengatakan bahwa yg sering terjadi pembullyingan di kelas X,IPS, karena anak kelas $\mathrm{X}$ ini jugak baru penyesuaian diri atau beradaptasi dilingkungan sekolah tersebut.

Melihat fenomena yang telah dibahas sebelumnya pada latar belakang di atas, maka peneliti tertarik untuk melakukan penelitian dengan judul "Dampak Perilaku Bullying Terhadap Self esteem DI SMAN 5 kota Pekanbaru tahun 2018".

\section{METODOLOGI PENELITIAN}

Desain penelitian kuantitatif dengan desain korelasional menggunakan pendekatan studi cross sectional. Pada studi cross sectional dimana subjek diobservasi satu kali saja melalui pengukuran atau pengamatan pada saat yang bersamaan dengan tujuan untuk melihat variabel bebas (Independent) dan terkait (Dependent). Variabel independen pada penelitian ini adalah perilaku bulying, variabel dependen adalah self esteem (harga diri). Penelitian ini dilaksanakan di SMAN 5 kota Pekanbaru, pada Juni 2018.

Populasi dalam penelitian ini adalah seluruh siswa SMAN 5 Kota Pekanbaru tahun ajaran 2016/2017 dengan jumlah 330 orang siswa kelas X. Teknik pengambilan sampel dilakukan secara snowball sampling, sebanyak 109 sampel.

Pengumpulan data primer dengan cara menyebarkan melalui serangkaian pengumpulan data dengan penyebaran kuesioner melakukan kepada responden sebanyak 109 siswa, Analisis data di lakukan secara univariat dan bivariat menggunkan uji chi-square.

\section{HASIL PENELITIAN}

Penelitian dilakukan di SMAN 5

Kota Pekanbaru September 2017-Juni 2018. Responden yang diambil berjumlah 109 orang dan menjawab secara lengkap, yang digambarkan melalui tabel dibawah ini: 
Tabel 1

Distribusi Frekuensi Responden

Berdasarkan Karakteristik Umur dan Jenis Kelamin di SMAN 5 Kota Pekanbaru Tahun 2018

\begin{tabular}{llcc}
\hline No & Variabel \& Kategori & Frekuensi & $\begin{array}{c}\text { Persentase } \\
(\%)\end{array}$ \\
\hline $\mathbf{1}$ & Umur & 68 & 62.4 \\
& a. $\quad 15-16$ tahun & 41 & 37.6 \\
\hline & b. $\quad$ 17-18 tahun & & \\
\hline $\mathbf{2}$ & Jenis Kelamin & 48 & 44.0 \\
& a. Laki-laki & 61 & 56.0 \\
\hline
\end{tabular}

Hasil analisis bahwa, dari 109 responden mayoritas responden berumur 15-16 tahun sebanyak 68 orang $(62.4 \%)$ dan berjenis kelamin perempuan sebanyak 61 orang $(56 \%)$.

Tabel 2

Distribusi Frekuensi Responden Berdasarkan Perilaku Agresif (Bullying) di SMAN 5 Kota Pekanbaru Tahun 2018

\begin{tabular}{cccc}
\hline NO & $\begin{array}{c}\text { Perilaku Agresif } \\
(\text { Bullying })\end{array}$ & Jumlah & $\begin{array}{c}\text { Persentase } \\
(\mathbf{\%})\end{array}$ \\
\hline $\mathbf{1}$ & Rendah & 56 & 51.4 \\
$\mathbf{2}$ & Tinggi & 53 & 48.6 \\
\hline & Total & $\mathbf{1 0 9}$ & $\mathbf{1 0 0 \%}$ \\
\hline
\end{tabular}

Hasil analisis menunjukan bahwa mayoritas responden sebagai korban bullying kategori rendah di SMAN 5 Kota Pekanbaru sebanyak 56 responden (51.4\%) dan hampir sebagian responden kategori korban bullying tinggi sebanyak 53 orang $(47 \%)$.

Tabel 3

$\begin{array}{llr}\text { Frekuensi } & \text { Responden } & \text { Berdasarkan } \\ \text { Distribusi } & \text { Frekuensi } & \text { Responden } \\ \text { Berdasarkan } & \text { Self Esteem } & \text { Di SMAN 5 } \\ \text { Kota PekanbaruTahun 2018 }\end{array}$

\begin{tabular}{cccc}
\hline $\begin{array}{c}\mathbf{N} \\
\mathbf{0}\end{array}$ & Self Esteem & Jumlah & $\begin{array}{c}\text { Persentase } \\
(\mathbf{\%})\end{array}$ \\
\hline $\mathbf{1}$ & Tinggi & 56 & 51.4 \\
\hline
\end{tabular}

\begin{tabular}{rrrl}
\hline $\mathbf{2}$ & Rendah & 53 & 48.6 \\
\hline & Total & $\mathbf{6 4}$ & $\mathbf{1 0 0 \%}$ \\
\hline
\end{tabular}

Hasil analisis menunjukan bahwa mayoritas responden dengan kategori self esteem tinggi di SMAN 5 Kota Pekanbaru sebanyak 56 orang $(51.4 \%)$.

\section{Tabel 4}

Hubungan Perilaku Agresif (Bullying) Terhadap Self Esteem di SMAN 5 Kota PekanbaruTahun 2018

\begin{tabular}{|c|c|c|c|c|c|c|c|c|c|}
\hline \multirow{3}{*}{$\begin{array}{l}\mathbf{N} \\
\mathbf{0}\end{array}$} & \multirow{3}{*}{$\begin{array}{l}\text { Perilaku } \\
\text { Agresif } \\
\text { (Bullying) }\end{array}$} & \multicolumn{4}{|c|}{ Self esteem } & \multicolumn{2}{|c|}{ Jumlah } & \multirow{3}{*}{$\begin{array}{l}\text { Nilai } \\
p \\
\text { value }\end{array}$} & \multirow{3}{*}{$\begin{array}{l}\text { OR } \\
(95 \% \\
\text { CI })\end{array}$} \\
\hline & & \multicolumn{2}{|c|}{ Tinggi } & \multicolumn{2}{|c|}{ Rendah } & \multirow[b]{2}{*}{$\mathbf{N}$} & \multirow[b]{2}{*}{$\%$} & & \\
\hline & & $\mathbf{N}$ & $\%$ & $\mathbf{N}$ & $\%$ & & & & \\
\hline 1 & Rendah & 36 & 64.3 & 20 & 35,7 . & 56 & 100 & 0,010 & 2.907 \\
\hline 2 & Tinggi & 20 & 37.7 & 33 & 62.3 & 53 & 100 & & $(1.362$ \\
\hline \multicolumn{2}{|c|}{ Jumlah } & 56 & 51.4 & 53 & 48.6 & 109 & 100 & & $6.474)$ \\
\hline
\end{tabular}

Terdapat hubungan yang erat korban bulltying tinggi dengan self esteem rendah dan terdapat hubungan yang erat korban bullying rendah terhadap self esteem tinggi pada siswa SMAN 5 Kota Pekanbaru.

Berdasarkan hasil uji statistik chisquare diperoleh nilai $\mathrm{p}$ value $=0,010$, pada nilai $\alpha 5 \%(0,05)$ yang berarti $\mathrm{p}$ value $<0,05$. Hal ini menunjukan bahwa hubungan perilaku agresif (bullying) terhadap self esteem remaja di SMAN 05 Kota Pekanbaru. Nilai Odds Ratio didapatkan 2.907 (1.373-6.464) artinya responden yang menjadi korban bullying tinggi umumnya lebih beresiko memiliki self esteem rendah di bandingkan dengan siswa SMA dengan perilaku bullying rendah.

\section{PEMBAHASAN}

\section{Karakteristik Responden Berdasarkan Umur dan Jenis Kelamin}

Hasil menunjukan bahwa, dari 109 responden mayoritas responden berumur 15-16 tahun sebanyak 68 orang (62.4\%). Umur atau usia adalah satuan waktu yang mengukur waktu keberadaan suatu benda atau makhluk, baik yang hidup maupun 
yang mati Menurut WHO, yang disebut remaja adalah mereka yang berada pada tahap transisi antara masa kanak-kanak dan dewasa. Batasan usia remaja menurut WHO adalah 12 sampai 24 tahun. Menurut Kementerian Kesehatan RI tahun 2010 usia remaja terbai dua yaitu masa remaja awal $12-16$ tahun dan masa remaja akhir 17-25 tahun (Kemenkes RI, 2012). Hasil penelitian didapatkan mayoritas responden pada usia remaja awal.

Responden berjenis kelamin perempuan sebanyak 61 orang $(56 \%)$, jenis kelamin merupakan perbedaan antara perempuan dengan laki-laki secara biologis sejak seseorang lahir. jenis kelamin berkaitan dengan tubuh laki-laki dan perempuan (Hungu, 2013). Perilaku bullying dapat ditemukan baik pada anak laki-laki maupun anak perempuan akan tetapi intensitasnya dipengaruhi oleh proses sosialisasi yang mereka terima, bukan karena adanya perbedaan tingkat keberanian dan ukuran fisik (Coloroso, 2012). Menurut Hertinjung dan Karyani (2015) bahwa anak laki-laki cenderung melakukan tindakan bullying dibandingkan anak perempuan. Anak laki-laki cenderung melakukan bullying dalam bentukbentuk agresi fisikal. Dikatakan juga bahwa anak laki-laki memiliki lebih banyak kebebasan untuk mengekspresikan perilaku agresif mereka sedangkan anak.

Damantari (2011) bullying dan victimization lebih sering terjadi pada anak laki-laki, hal yang sama juga disebutkan bahwa perilaku bullying lebih menonjol terjadi pada kalangan laki-laki daripada perempuan. Hal tersebut sejalan dengan pendapat Dagun (2013) bahwa laki-laki memiliki karakteristik yang sangat agresif, sangat dominan, sangat aktif, menyukai kompetisi dan menyukai situasi agesif selain itu laki-laki juga tidak peka terhadap perasaan orang lain, sedangkan perempuan tidak agresif, cenderung pasif dan penuh kasih sayang, tidak menyukai situasi yang agresif, dan peka terhadap perasaan orang lain.Hasil penelitain didapatkan mayoritas responden dengan jenis kelamin perempuan dan sebagiannya laki-laki.

\section{Hubungan Perilaku Agresif (Bullying) Terhadap Self Esteem}

Terdapat hubungan yang erat korban bulltying tinggi dengan self esteem rendah dan terdapat hubungan yang erat korban bullying rendah terhadap self esteem tinggi pada siswa SMAN 5 Kota Pekanbaru.

Berdasarkan hasil uji statistik chisquare diperoleh nilai $\mathrm{p}$ value $=0,006$, pada nilai $\alpha 5 \%(0,05)$ yang berarti $p$ value $<0,05$. Hal ini menunjukan bahwa hubungan perilaku agresif (bullying) terhadap self esteem remaja di SMAN 05 Kota Pekanbaru. Nilai Odds Ratio didapatkan 2.907 (1.373-6.464) artinya responden yang menjadi korban bullying tinggi umumnya lebih beresiko memiliki self esteem rendah di bandingkan dengan siswa SMA dengan perilaku bullying rendah.

Menurut Usman (2013) tindakan kekerasan dan perilaku bullying banyak muncul pada remaja di kalangan pelajar sekolah, hal tersebut dikarenakan pada masa remaja muncul sifat egoisentrisme yang tinggi. Meskipun begitu di masa ini seorang remaja diharapkan mampu untuk mengontrol perasaan mereka serta mampu untuk mengendalikan dan memahami gejolak emosi sehingga akan tercapai kondisi emosional yang adaptif dengan begitu remaja akan mampu menyelesaikan tugas-tugas perkembangan dengan baik (Paramitasari \& Alfian, 2012). Keinginan kuat remaja untuk menjadi pusat perhatian juga membuat remaja melakukan hal-hal yang dapat menarik perhatian orang lain, salah satu bentuk perilaku menarik perhatian orang lain di masa remaja yaitu perilaku bullying, remaja yang melakukan bullying untuk membuat orang lain memperhatikannya (Halimah, dkk, 2015).

Perilaku bullying adalah tindakan yang dilakukan untuk menyakiti orang lain, tindakan tersebut berupa mengungkapkan hal-hal yang 
menyakitkan, mengolok-olok, atau memanggil nama dengan panggilan yang menyakitkan, mengabaikan atau mengucilkan dari kelompok permainan, memukul, menendang, mendorong, mengancam, menyebarkan gosip, dan menyebarkan pernyataan-pernyataan dengan tujuan membuat korban tersakiti. Bullying juga dikatakan sebagai sebuah tindakan yang dilakukan oleh seseorang kepada orang lain dengan tujuan menyakiti orang tersebut dan dilakukan secara berulang dari waktu ke waktu, dimana pihak yang tersakiti disebut dengan korban (Hassan \& Ee, 2015). Remaja melakukan perilaku bullying sebagai salah satu bentuk untuk mencapai perhatian dari orang lain, ingin menunjukkan eksistensi diri, dan ingin menutupi kekurangan diri.

Teori psikologi yang dikemukakan oleh Adler (dalam Feist \& Feist, 2012). sesorang menutupi kekurangan diri merupakan suatu bentuk perasaan inferioritas akibat aktualisasi diri yang tidak terpenuhi. Perasaan inferioritas yang berlebihan pada akhirnya membuat seseorang berjuang untuk mencapai kepentingan pribadi, menetapkan tujuan yang tinggi sehingga tidak realistis, kemudian agresi yang muncul untuk melindungi harga diri mereka yang rapuh sehingga agresi dapat membentuk depresiasi yaitu kecenderungan untuk menilai rendah pencapaian orang lain dan menganggap tinggi apa yang dicapai oleh diri sendiri, selain itu dapat berupa dakwaan yakni menyalahkan ataupun menekan orang lain untuk membalas orang lain dalam rangka untuk melindungi self esteem yang lemah.

Remaja yang memiliki self esteem yang tinggi akan memiliki perilaku bullying yang rendah. Hal ini disebabkan karena remaja dengan self esteem yang tinggi akan merasa puas dengan apa yang dimilikinya sehingga menghasilkan percaya diri, rasa bangga, rasa kuat, dan perasaan berguna (Feist \& Feist, 2012). Selain itu dengan self esteem yang tinggi seseorang akan cenderung memfokuskan diri pada kekuatan atau kelebihan yang mereka miliki dan mampu mengingat peristiwa yang menyenangkan sehingga akan membantu individu tersebut untuk mempertahankan evaluasi positif terhadap dirinya dan mengarahkan kepada hal-hal serta perilaku yang juga positif (Browne dalam Baron \& Byrne, 2012). Sedangkan individu dengan self esteem rendah lebih mudah mengekspresikan kemarahannya secara terbuka sehingga akan mempertahankan evaluasi negatif dirinya (Brownie dalam Baron \& Byrne, 2012). Self esteem yang rendah akan mendorong individu kedalam perasaan inferioritas yang berlebihan akibat dari aktualisasi diri yang tidak dapat terpenuhi sehingga membuat seseorang akan berjuang untuk mencapai kepentingan pribadi, menetapkan tujuan yang tinggi dan tidak realistis yang kemudian membuat dorongan agresi muncul untuk melindungi harga diri mereka yang rapuh sehingga agresi dilakukan untuk membentuk reaksi depresiasi yaitu kecenderungan untuk menilai rendah pencapaian orang lain dan menganggap tinggi apa yang dicapai oleh diri sendiri, selain itu dapat berupa reaksi dakwaan dengan menyalahkan/ menekan orang lain untuk membalas orang lain dalam rangka untuk melindungi self esteem mereka yang lemah (Feist \& Feist, 2012).

Penelitian ini sejalan dengan Zainab (2017) hubungan antara perilaku bullying pada remaja dengan self esteem. Penelitian ini dilakukan di SMP Swasta di kota Surakarta. Subjek penelitian atau responden pada penelitian ini adalah 100 subjek yang terdiri dari 50 remaja putra dan 50 remaja putri. Pengambilan sampel dilakukan dengan teknik cluster random sampling. Metode yang digunakan dalam penelitian ini adalah metode kuantitatif dengan alat ukur berupa skala perilaku bullying dan skala self esteem. Teknik analisis data yang digunakan dalam penelitian ini adalah korelasi Product Moment dari Pearson dan analisis dengan menggunakan t-test. Berdasarkan hasil analisis data dengan korelasi product 
moment diperoleh nilai koefisien korelasi $\left(\mathrm{r}_{\mathrm{xy}}\right)=-0,292$ dengan taraf signifikansi $=$ $0,002(\mathrm{p}<0,01)$ yang berarti ada hubungan negatif antara self esteem dengan perilaku bullying pada remaja.

Penelitian terdahulu juga mengungkapkan terdapat hubungan yang signifikan antara self esteem dan perilaku bullying, hubungan tersebut cenderung berbanding terbalik yakni jika self esteem tinggi maka perilaku bullying akan cenderung rendah dan sebaliknya (Septrina dkk, 2009). Menurut Erol dan Orth (2011) dikatakan bahwa seseorang yang pada masa remaja memiliki self esteem yang rendah atau negatif maka remaja tersebut akan cenderung memiliki perilaku-perilaku yang juga negatif, self esteem yang rendah pada masa remaja dapat menyebabkan kesehatan mental yang buruk, keadaan fisik yang lebih buruk, dan resiko kejahatan kriminal yang lebih tinggi. Maka dapat diartikan bahwa self esteem merupakan salah satu faktor yang mempengaruhi perilaku bullying pada remaja. Tingkat self esteem dalam penelitian ini termasuk kedalam kategori tinggi, sedangkan tingkat perilaku bullying pada remaja dalam penelitian ini termasuk kategori yang rendah.

Hasil penelitian juga Pendapat diatas didukung oleh penelitian yang menyatakan bahwa self esteem yang rendah diduga memiliki kecenderungan menjadi rentan terhadap depresi, penggunaan narkoba dan dekat dengan perilaku bullying (Srisayekti dkk, 2015). Dengan kata lain individu yang memiliki self esteem yang rendah rentan terhadap perilaku bullying dibandingkan dengan individu yang memiliki self esteem yang tinggi.

Penelitian dilakukan oleh Annisa (2012) yang menyatakan bahwa self esteem menjadi salah satu faktor penyebab munculnya perilaku bullying pada remaja, yang menyatakan bahwa terdapat hubungan yang signifikan antara self esteem dan perilaku bullying, semakin tinggi self esteem maka semakin rendah perilaku bullying, artinya self esteem turut menjadi salah satu faktor munculnya perilaku bullying pada remaja. Namun terdapat faktor lain yang juga mempengaruhi perilaku bullying yaitu pola asuh orangtua, norma kelompok dan iklim sekolah.

Asumsi peneliti berdasarkan teori dan penelitian terkait, kaitan antara perilaku agresif (bullying) dengan self esteem sangat erat dimana semakin tinggi tingkat bullying maka akan semakin rendah self esteem seseorang dan sebaliknya semakin rendah perilaku agresif (bullying) maka akan semakin baik keadaan self esteem seseorang.

\section{Keterbatasan Penelitian}

Responden dengan jumlah yang besar membuat peneliti kewalahan dalam mengontrol keseriusan responden, sehingga peneliti harus ekstra dalam mengontrol keseriusan responden ketika mengisi kuisioner.

Penelitian ini hanya mengkaji kaitan antara perilaku agresif (bullying) terhadap self esteem, tetapi tidak mampu mengkaji faktor-faktor lain dari penyebab rendahnya self esteem seoarang remaja.

\section{PENUTUP}

\section{Kesimpulan}

Karakteristik responden dari 109 responden mayoritas responden berumur 15-16 tahun sebanyak 68 orang $(62.4 \%)$ dan berjenis kelamin perempuan sebanyak 61 orang $(56 \%)$.

Sebagian besar responden sebagai korban bullying kategori rendah di SMAN 5 Kota Pekanbaru sebanyak 56 responden $(51.4 \%)$.

Sebagian besar responden dengan kategori self esteem tinggi di SMAN 5 Kota Pekanbaru sebanyak 56 orang (51.4\%).

Ada hubungan yang erat antara perilaku agresif (bullying) terhadap self esteem, dimana semakin rendah korban bullying maka akan semakin tinggi tingkat 
self esteem dan semakin tinggi korban bullying maka akan semakin rendah tingkat self esteem.

\section{Saran}

Diharapkan penelitian ini dapat memberi pengetahuan dan wawasan bagi responden yaitu remaja, sehingga dapat menurunkan tingkat perilaku agresif (bullying) sesama remaja.

Diharapkan kepada SMAN 5 Kota Pekanbaru agar dapat dapat memantau dan memberikan pendidikan tentang efek negatif dari perilaku agresif bullying pada sesama usi remaja.

Diharapkan dapat menjadi sumber informasi bagi peniliti selanjutnya dan diharapkan peneliti selanjutnya agar dapat meneliti faktor-faktor lain yang dapat mempengruhi self esteem remaja.

\section{DAFTAR PUSTAKA}

Anderson S, Wilson Lorraine M, (2011).Patofisiologi Konsep Klinis Proses-Proses Penyakit, Jakarta : Penerbit Buku Kedokteran EGC

Boeree, G.C., (2006). Personality theories. Retrieved August 12, 2014, from http://webspace.ship.edu/cgboe r/maslow.html

Data Riau (2017). Siswa 05 Kota Pekanbaru Korban Bullying Melapor Kekantor Walikota. Pekanbaru. Data Riau

Fitrian, (2016). Hubungan Antara Konsep Diri dengan Bullying Pada Siswa/I SMPN 16 Samarinda. Yogyakarta. Stikes Aisyisiah.

Hurlock B.E,. (2006). Perkembangan Anak. Jakarta: Penerbit Erlangga.
Kemenkes RI. (2014). Riskedas Tahun 2013( Riset Kesehatan Dasar). Jakarta. Kemenkes RI

Misdiarly, (2007). Diabetes Melitus. . Jakarta. Yayasan Obor Indonesia

Meyske (2017), hubungan obesitas dengan harga diri pada remajadi SMA Negeri 1 Limbodo. Manado Universitas Sam Ratulngi. Jurnal Vol.5. No.1

Monks, F.J., Knoers, A.M.P., \& Haditono, S.R. (2012). Psikologi Perkembangan (Pengantar Dalam Berbagai Bagiannya). Yogyakarta: Gadjah Mada University Press.

Muadz, M.M, dkk. 2011. Kesehatan Reproduksi Remaja dan Wanita. Salemba Medika : Jakarta

Nadjibah, Y. (2017). Kupas Tuntas Obesitas. Solo. PT Tiga Serangkai Pustaka Mandiri

Notoatmodjo, S. (2010). Metodologi Penelitian Kesehatan. Jakarta: PT Rineka Cipta.

Parsons, L.( 2009). Bullied Teacher Bullied Student: Mengenali Budaya Kekerasan Disekolah Anda dan Mengatasinya .Jakarta : PT Grasindo.

Partowisastro, K. (2007). Dinamika dalam Psikologi Pendidikan. Jakarta: Erlangga

Priyatna, A. (2010). Lets End Bullying” Memahami, Mencegah Dan Mengatasi Bullying. Jakarta: PT Elex Media Komputindo.

Proverawati Atikah. (2010). Obesitas dan Gangguan Perilaku Makan pada Remaja. Jakarta: Muha Medika. 
Ramadani Melati, (2011). Hubungan

HargaDiri dengan Kemampuan

Aktualisasi

Diri.

http://repository.usu.ac.id/handle/1234567

$89 / 27522$

Riwidikdo, H. (2008). Statistik Kesehatan. Yogyakarta: Mitra Cendikia Press

Santrock, J, W.(2009). Perkembangan Anak. Jakarta. Erlangga.

Sejiwa, (2008). Bullying Mengatasi Kekerasan di Sekolah dan Lingkungan Sekitar Anak. Jakarta: PT Grasindo.

Septrina (2009). hubungan tindakan bullying di sekolah dengan self esteem siswa. Depok.niversitas Gunadarma. Jurnal Vol 3.ISSN 1885-2559

Setyawati. (2006). Asuhan Keperawatan Keluarga. Yogyakarta: Mitra Cendikia Press.

Suparno, P. (2007). Teori Perkembangan Kognitif Jean Piaget. Jogjakarta.

Penerbit Kanisius 